\title{
Intelligent distributed production control
}

\author{
André Thomas - Damien Trentesaux • \\ Paul Valckenaers
}

Received: 17 October 2011 / Accepted: 1 November 2011 / Published online: 10 November 2011

(C) Springer Science+Business Media, LLC 2011

\begin{abstract}
This editorial introduces the special issue of the Springer journal, Journal of Intelligent Manufacturing, on intelligent distributed production control. This special issue contains selected papers presented at the 13th IFAC Symposium on Information Control Problems in ManufacturingINCOM'2009 (Bakhtadze and Dolgui 2009). The papers in this special issue were selected because of their high quality and their specific way of addressing the variety of issues dealing with intelligent distributed production control. Previous global discussions about the state of the art in intelligent distributed production control are provided, as well as exploratory guidelines for future research in this area.
\end{abstract}

Keywords Distributed control · Intelligent control · Manufacturing $\cdot$ Prospects

\footnotetext{
A. Thomas

Research Centre for Automatic Control (CRAN), CNRS

(UMR7029), Nancy University, 27, rue du merle blanc, 88000 Epinal, France

e-mail: Andre.Thomas@cran.uhp-nancy.fr

D. Trentesaux

Université Lille Nord de France, 59000 Lille, France

D. Trentesaux $(\varangle)$

UVHC, TEMPO-Lab, Le mont houy, 59313 Valenciennes

Cedex 9, France

e-mail: Damien.Trentesaux@univ-valenciennes.fr

P. Valckenaers

K.U. Leuven-Mechanical engineering Celestijnenlaan 300,

3001 Leuven, Belgium

e-mail: Paul.Valckenaers@mech.kuleuven.be
}

\section{Introduction}

The Springer journal, Journal of Intelligent Manufacturing, presents a special issue (SI) on intelligent distributed production control. This SI contains selected papers presented at the 13th IFAC Symposium on Information Control Problems in Manufacturing-INCOM'2009 (Bakhtadze and Dolgui 2009). The symposium took place in Moscow (Russia) from June 3rd to 5th, 2009. It was organized by the V.A. Trapeznikov Institute of Control Sciences of the Russian Academy of Sciences and sponsored by International Federation of Automatic Control (IFAC), International Federation for Information Processing (IFIP), Russian Academy of Sciences (RAS) and the research group, Modeling, Analysis and Control of Dynamic Systems, at the French National Center for Scientific Research (GDR MACS/CNRS). For a long time, the international community has addressed the production control's intelligent distributed issues, especially the IFAC, and this conference gave us the opportunity to propose a special issue devoted to this topic.

This editorial is organized as follows. First, intelligent distributed production control is introduced as a key concept for future research. Then, this SI presents and discusses a set of major issues. The papers are introduced as possible ways to address some of these issues. This editorial concludes with a set of short-term and long-term prospectives for future research.

\section{Stakes and current issues in intelligent distributed production control}

Historically, "centralized" approaches, based on the federative concept of Computer Integrated Manufacturing (CIM), have been implemented, using Manufacturing Resources 
Planning (MRP2) systems and, more recently, Enterprise Resources Planning (ERP) systems, with tools and methods based on operational research about production control. In centralized approaches, the decision-making is hierarchically broadcast from the higher decisional levels down to the operational units. The success of these approaches lies mainly in their ability to provide long-term optimization of production planning and scheduling, given a relatively stable industrial context.

Faced with the market challenges in the 1980s, other decision-making philosophies and strategies emerged. Requirements for more flexibility and more reactivity led to the implementation of the first "distributed" approaches, such as anthropocentric and visual management methods (e.g., kanban, operator empowerment). Unfortunately, these new ways to pilot and control the material flows have led to "black boxes" in management systems, thus highlighting the need for more real-time closed-loop information systems. Klein (2008) showed that, in kanban systems, very short-term priority management is always a key issue.

In the 1990s, Production and Supply Chain Systems changed from the traditional mass production led by products to mass customization in order to deal with increasing global market competition. High competition between companies and market volatility then forced companies to be more agile (Christopher 1992). From the point of view of production control, agility may be seen as the ability to operate with a high level of coordination and proactivity throughout the supply chain, simultaneously reacting to disturbances on the shop floor efficiently while taking the increasing process complexity (e.g., variabilities, high product variety, reconfiguration issues) into account.

Following the improvements in information technology, progressively, it seems obvious that giving the physical system entities (e.g., parts, resources) some decision-making capabilities could be a new way to deal with this still unsolved issue. One argument was that, in centralized approaches, the time spent to inform the correct controller within the hierarchy (bottom-up) and then to decide how to resolve the problem and apply the decision (top-down) generated lags and instabilities. Another argument was that these centralized approaches, despite their ability to provide near-optimal behavior in fully static and deterministic environments, could not easily deal with disturbances and could not easily evolve with the environment. The constantly increasing power of the central calculator could hardly handle the complexity induced.

Even though ERP systems are now widespread, these systems do not fully satisfy industrial needs, which are always seeking for more agility. A recent study highlighted that, for European factory equipment suppliers, the priority among 10 major concerns was the need for "intelligent products", including self-optimizing systems [Schreiber (2007) cited in
Sauer (2008)]. Industrial requirements have clearly evolved from the common traditional performance criteria, described in terms of static optimality or near-optimality, towards new performance criteria, described in terms of reactivity, adaptability and robustness. A growing number of industrialists now want control systems that provide satisfactory, adaptable and robust solutions rather than optimal solutions that require meeting several hard assumptions.

Consequently, since 1990s, the increased research in manufacturing systems control has moved from traditional centralized approaches to distributed architectures. Among others, fully heterarchical architectures promote production control by distributing each decision capacity to autonomous entities, without any centralised view of the status of the shop floor elements. In order to insure consistency of decision-making, more pragmatic approaches based on hybrid control combining the predictability of the centralized control with the agility and robustness against disturbances of the heterarchical control have been designed, allowing the integration of optimization models with features of cooperation and local autonomy. To name a few, the concepts of Holonic Manufacturing Systems (HMS) (Babiceanu and Chen 2006), Product Driven Systems (PDS) (Pannequin et al. 2009) and Agent-Based Manufacturing (Maturana et al. 1999) have been proposed to design future manufacturing systems. These concepts argue that the products-and more globally, all the production resources - can be modeled as an association between two parts: a physical part and an informational one. These intelligent systems will assist operators and managers in manufacturing and supply chain control.

The common denominator for all these approaches is to bring intelligence and autonomy as near as possible to, or even in, the physical system. The idea is to permit the decisional entities to work together so that they can react quickly and autonomously, within constraints, instead of requesting control decisions from the upper decisional levels, which was generating response time lags. In these distributed approaches, other interaction processes than coordination appear, essentially negotiation and cooperation (Marik and Lazansky 2007). However, negotiation and cooperation led to new problems, for example, the need to have deadlock avoidance mechanisms and, more generally, the need to prove that sufficient level of performance can be attained. As a result, the maturity level of these distributed approaches is still low, complicating, even preventing, their real implementation.

Four challenges need to be addressed to reach a sufficient maturity level (Trentesaux 2009): performance guarantees (How to demonstrate the abilities of intelligent distributed control?), emergence engineering (How to control the emerging behavior in a desirable way?), interoperability and norms (How can intelligent distributed control be integrated and interfaced with the existing information systems?), and 
development, scalability and costs (How can industrialists implement an intelligent distributed control system and measure their return-on-investment compared to traditional centralized solutions?).

Despite this lack of maturity, the research in this area, as well as the industrial interest, are currently increased by several new technologies and software developments, potentially offering new abilities that can be used to increase flexibility and reactivity. Faced with these new trends, many new research projects are focusing on identification technologies, such as electronic or biometric technologies. Radio Frequency IDentification (RFID) technology represents a quick, safe way to track products, opening the way for linking informational and physical flows, which still remains an important research challenge (Ploss1 1993) and providing an accurate, real-time vision of the shop floor. In addition, more and more efforts are being put into developing the norms that will allow intelligent distributed production control to be implemented (e.g., International Industrial Standard IEC61499, the IEEE Foundations for Intelligent Physical Agents (FIPA) Standards Committee). These new technologies appear to be a catalyst to change the fifty-year-old way of controlling production through traditional MRP2 systems (Thomas et al. 2008).

\section{The contributions}

In this SI, 11 papers were selected after a robust peer review process involving reviewers from the INCOM conference to evaluate the papers' improvements and new reviewers from the Journal of Intelligent Manufacturing community. These papers are briefly introduced below.

Aissani, Bekrar, Trentesaux, and Beldjilali propose a model for adaptive scheduling in multi-site companies. A multi-agent approach is adopted in which intelligent agents have reactive learning capabilities based on reinforcement learning. Experimentation and simulations inspired from a real case study demonstrate the applicability and the effectiveness of the model in terms of both optimality and reactivity.

In Khalgui, Mosbahi, Hanisch, and $\mathrm{Li}$, the authors define an architecture of reconfigurable multi-agent systems in which a Reconfiguration Agent is assigned to each device of the execution environment to apply local reconfigurations, and a Coordination Agent is proposed for the coordination between devices in order to guarantee safe, satisfactory distributed reconfigurations.

The paper by Leitão, Mendes, Bepperling, Cachapa, Colombo, and Restivo discusses the integration of 2D/3D digital software tools with Petri-net-based service-oriented frameworks to allow the design, configuration, analysis, validation, simulation, monitoring and control of manufacturing systems in a virtual environment and its posterior smooth migration into the real "physical" environment.

Ostrosi, Fougères, Ferney, and Klein propose a Fuzzy Configuration Grammar based on agents to assist collaborative and distributed design for product configuration. Based on the distributed fuzzy models and fuzziness of interactions during the collaborative and distributed design for configuration, a computational approach for product configuration is developed.

Pannequin, and Thomas propose another interpretation of stigmergy for product-driven architectures. In this paper, the authors advise coming back to the basics: the information (i.e., pheromone) attached to the products. They present agent-oriented components that implement stigmergic design patterns. These components are first applied to a laboratory platform and then to an industrial test case.

In their paper, Radakovič, Obitko, and Mařík discuss the need for explicit definitions of both declarative and procedural knowledge and propose to handle procedural knowledge explicitly. They discuss sharing and distributing such knowledge, and they give an example of an implemented transportation system. They also introduce an architecture for explicit specification of agent behavior in handling failure patterns and configuring smart grids.

To develop daily assignments of employees to workstations in a workshop and propose a production schedule, Sabar, Montreuil, and Frayret propose a multi-agent algorithm for personnel scheduling and rescheduling in a dynamic environment of a fast-paced multi-product assembly center.

The paper of Saint Germain, Valckenaers, Van Belle, Verstraete, and Van Brussel presents a decision-making pattern that uses trust mechanisms based on past performance. These authors infer how information is to be understood and the uncertainty regarding the expected behavior. This decisionmaking pattern allows the cooperation in large systems of systems without requiring conventional integration.

Tounsi, Habchi, Boissière and Azaiez analyze and model supply chains in the particular context of small and medium enterprises in the field of mechatronics. They propose a generic metamodel for supply chains and formalize the dynamic behavior of the metamodel's concepts.

The tracking of self-moving products is a major challenge. Véjar, and Charpentier present a general framework for location and manufacturing applications with the objective of reproducing the manufacturing system dynamic in an adaptive simulation.

Villaseñor Herrera, Vidales Ramos, and Lastra describe the specification of a WebService-enabled Decision Support System, using a set of software agents. The agent-based system presented in their paper is capable of supporting the dynamic composition and orchestration of WebServices exposed by control devices for discrete manufacturing systems. 


\section{Prospectives for intelligent distributed production control}

From the challenges introduced in the Introduction and our knowledge about the current research activity in intelligent distributed production control, we can extrapolate some possible future productive research activities in this area.

\section{Bio-inspiration}

It seems to us that all intelligent distributed approaches want to mimic nature and human behavior in their ability to selforganize and adapt to unexpected situations. Bio-inspiration can be seen to have two levels. The first one concerns the system's lower decisional level. It would be interesting to go further into bio-inspiration to exploit the maximum from the existing solutions found in the nature. Genetic algorithms, particle swarm, potential fields, bee algorithms, bat intelligence, and stigmergy, to name but a few, are typical approaches that can be studied in depth from an intelligent distributed control perspective. The second level can be seen from the global perspective: the architecture. The studied system can be structured in the same way as the human body. The Viable System Model (VSM), proposed by Beer (1984), is particularly characterized by its recursivity property. This VSM could be an interesting way to structure and organize the agent communities. The paper of Pannequin and Thomas illustrates this prospective.

Nature provides instantiations of avoiding group-selfishness. For example, in social insect colonies, all members are genetically related because the queen generates all offspring so the colony needs to avoid selfishness. This provides the inspiration for decentralized design to avoid selfish routing and to make decisions by individual intelligent products.

\section{Closed-loop PLM and intelligent products}

The concept of intelligent product could be generalized to the whole product life cycle, and not only specifically in the production phase, which is mainly addressed by the research community. The promising concept of closed-loop Product Life-cycle Management (PLM) would typically gain from using intelligent or distributed control system. For example, an intelligent product could enhance the exchange of information and feedback toward the different phases of the product's life cycle and the next product generation (e.g., from maintenance to re-design, from exploitation to production) (Sallez et al. 2010). PLM could be generalized to many industrial areas and/or complex systems, especially in the health care sector or in the construction sector, opening the way toward Product Service Systems (PSS) (Morelli 2006). In the health care sector, intelligent entities could be used to increase the patient's knowledge via informa- tional capabilities (e.g., the medicine to be dispensed or the possible contra-indications). In the construction sector, Building Information Modeling (BIM), well-known in this sector, could be easily enhanced or implemented using intelligent embedded systems (e.g., intelligent parts integrated in the building for safety, maintenance or traceability purposes).

Sustainability and distributed control

The concept of distributed control can also be useful to improve the sustainability of production system, for example, by embedding energy consumption management tools into products and resources. A resource would autonomously shut down its power system when required or adapt its scheduling in terms of new decision criteria, including energy savings, which is too complex to manage with a centralized approach. The dynamic pricing of electricity can also be more easily managed in a distributed way in production systems. The energy grid of a region can also be studied from a distributed production control perspective.

\section{The VIP model}

When observing non-automated production, the archetypical production lines (i.e., Modern Times with Charlie Chaplin) need to be redesigned for every new product model; the workforce needs training to deal with this redesigned line. In the automated version, this means major software maintenance for every introduced product, even non-trivial variations. This is not a feasible option economically. In contrast, very wealthy customers, called VIPs, are served by a different model/organization. Every customer has an agent, called a butler, who searches for and combines high-quality services from best-in-class providers to fulfill the customer's needs. The butler also supervises the execution of the services and handles any contingency. In this organization, when a new product is introduced, no special actions are required; it is business as usual. Therefore, this VIP organization will be targeted for future manufacturing organizations, which implies the presence of intelligent products (i.e., the butlers) and intelligent services. This is a system design in which neither the product or the equipment decides; it is a choreography in which the interactions make the decisions emerge. The intelligent entities are the primary self-experts, which is what makes such systems cope with change.

\section{Open systems}

The obsession with performance evaluation has led to the predominance of closed-system designs. The performance of an open system cannot be readily measured. It is like 
trying to measure travel-distance performance of a navigation system that only delivers the maps, but not the routing mechanisms. Nonetheless, real progress in uncertain and complex environments will require the design and development of these open systems. In particular, the infrastructure design reproducing the stable aspects and elements on which full systems can be built rapidly and efficiently requires that the research community learn how to study this type of design. The industrial counterpart of this ambition can be observed in reports on best practices and the needs expressed by senior personnel. For instance, in the Manufacturing Execution System (MES) domain, industrials prefer visibility (i.e., to have a kind of production radar at their disposal, informing them about what will happen in the near future) over optimization (i.e., sophisticated systems that make decisions based on too little or incorrect/stale information and limited information models).

\section{ERP and distributed control}

ERP systems would gain from the ability to interoperate with autonomous products and resources. One well-known limitation of ERP systems is the inability to handle the events at the lower level of production, and one wellknown ability of distributed control is its reactivity in such a context. One well-known limitation of distributed control is its temporal or spatial myopia (i.e., its lack of visibility in the future or in the data space), while one wellknown ability of ERP systems is their aptitude for optimizing long-term plans (Zambrano et al. 2011). It would be interesting to integrate and articulate the two concepts: the upper decision level would be managed using an ERP system, bounding the decisions at the lower level but not explicitly, while the lower level would be managed in a distributed autonomous way, in which local reactive decisions at the MES level, bounded by the ERP system, would help to handle unexpected events with a long-term view.

Acknowledgments The guest editors acknowledge their debt to the authors and reviewers of this special issue. For their confidence in this project, the guest editors address special thanks to Andrew Kusiak, Editor-in-Chief; Natalia Bakhtadze, Chair of the National Organizing Committee; and Alexandre Dolgui, Chair of the International Program Committee.

\section{List of the 11 papers composing this special issue}

Aissani N., Bekrar A., Trentesaux D., \& Beldjilali B., Dynamic scheduling for multi-site companies: A decisional approach based on reinforcement multi-agent learning. Journal of Intelligent Manufacturing, http://dx.doi.org/10.1007/s10845-011-0580-y.

Khalgui M., Mosbahi O., Hanisch H-M., \& Li Z., A multi-agent architectural solution for coherent distributed reconfigurations of function blocks. Journal of Intelligent Manufacturing, http://dx. doi.org/10.1007/s10845-011-0556-y.

Leitão P., Mendes J. M., Bepperling A., Cachapa D., Colombo A. W., \& Restivo F., Integration of virtual and real environments for engineering service-oriented manufacturing systems. Journal of Intelligent Manufacturing, http://dx.doi.org/10.1007/ s10845-011-0591-8.

Ostrosi E., Fougères A. -J., Ferney M., \& Klein D., A fuzzy configuration multi-agent approach for product family modelling in conceptual design. Journal of Intelligent Manufacturing, http:// dx.doi.org/10.1007/s10845-011-0541-5.

Pannequin R., \& Thomas A., Another interpretation of stigmergy for product-driven systems architecture. Journal of Intelligent Manufacturing, http://dx.doi.org/10.1007/s10845-011-0588-3.

Radakovič M., Obitko M., \& Mařík V., Dynamic explicitly specified behaviors in distributed agent-based industrial solutions. Journal of Intelligent Manufacturing, http://dx.doi.org/10.1007/ s10845-011-0593-6.

Sabar M., Montreuil B., \& Frayret J. -M., An agent-based algorithm for personnel shift-scheduling and rescheduling in flexible assembly lines. Journal of Intelligent Manufacturing, http://dx. doi.org/10.1007/s10845-011-0582-9.

Saint Germain B., Valckenaers P., Van Belle J., Verstraete P., \& Van Brussel H., Incorporating trust in networked production systems. Journal of Intelligent Manufacturing, http://dx.doi.org/10.1007/ s10845-011-0597-2.

Tounsi J., Habchi G., Boissière J., \& Azaiez S., A multiagent knowledge model for SMEs mechatronic supply chains. Journal of Intelligent Manufacturing, http://dx.doi.org/10.1007/ s10845-011-0537-1.

Véjar A., \& Charpentier P., Generation of an adaptive simulation driven by product trajectories. Journal of Intelligent Manufacturing, http://dx.doi.org/10.1007/s10845-011-0504-x.

Villaseñor Herrera V., Vidales Ramos A., \& Lastra J. L. M., An agentbased system for orchestration support of web service-enabled devices in discrete manufacturing systems. Journal of Intelligent Manufacturing, http://dx.doi.org/10.1007/s10845-011-0539-z.

\section{Other references}

Babiceanu, R., \& Chen, F. (2006). Development and applications of holonic manufacturing systems: A survey. Journal of Intelligent Manufacturing, 17, 111-131.

Bakhtadze, N., \& Dolgui, A. (Eds.) In Information control problems in manufacturing 2009: The proceedings of the 13th IFAC international symposium, Moscow, June, 3-5 2009, Elsevier Science, IFACPapersOnline.net (ISSN 1474-6670, ISBN 978-3-90266143-2). http://incom09.org.

Beer, S. (1984). The viable system model: Its provenance, development, methodology and pathology. Journal of the Operational Research Society, 35, 7-25.

Christopher, M. (1992). Logistics and supply chain management. Pitman: Financial Times.

Klein, T. (2008). Le kanban actif pour assurer l'interoperabilité décisionnelle centralisé/distribué. Application a un industriel de l'ameublement, PhD thesis, Université Henri Poincaré, Nancy I.

Marik, V., \& Lazansky, J. (2007). Industrial applications of agent technologies. Control Engineering Practice, 15, 1364-1380.

Maturana, F., Shen, W., \& Norrie, D. (1999). MetaMorph: An adaptive agent-based architecture for intelligent manufacturing. International Journal of Production Research, 37(10), 2159-2173.

Morelli, N. (2006). Developing new product service systems (PSS): Methodologies and operational tools. Journal of Cleaner Production, 14, 1495-1501. 
Pannequin, R., Morel, G., \& Thomas, A. (2009). The performance of product-driven manufacturing control: An emulation-based benchmarking study. Computers in Industry, 60, 195-203.

Plossl W. G. (1993) La nouvelle donne de la gestion de la production - Afnor gestion, Paris

Sallez, Y., Berger, T., Deneux, D., \& Trentesaux, D. (2010). The lifecycle of active and intelligent products: The augmentation concept. International Journal of Computer Integrated Manufacturing, 23(10), 905-924.

Sauer, O. (2008). Automated engineering of manufacturing execution systems: A contribution to "adaptivity" in manufacturing companies. In 5th CIRP-sponsored international conference on digital enterprise technology, Nantes, France, October 22-24, 2008.

Schreiber, W. (2007). Die Top-Themen der deutschen AutomobilIndustrie. In Manufuture Germany Konferenz: die strategische Forschungsagenda, Deutschland, September 2007 (pp. 90-94).
Thomas, A., Genin, P., \& Lamouri, S. (2008). Mathematical programming approaches for stable tactical and operational planning in supply chain and aps context. Journal of Decision Systems, 17, 425-455.

Trentesaux, D. (2009). Distributed control of production systems. Engineering Applications of Artificial Intelligence, 22(7), 971-978.

Zambrano, G-M., Pach C., Aissani N., Berger T., \& Trentesaux D. (2011). An approach for temporal myopia reduction in heterarchical control architectures. In 2011 IEEE international symposium on industrial electronics (pp. 1767-1772), June 2011. Poland: Gdansk University Of Technology. 